\title{
Exploring Acronym in Indonesian Language; Structure Formation and Internal Syllable
}

\author{
Susy Deliani \\ Kopertis Wilayah I Medan Indonesia
}

\begin{abstract}
This study analyzed the process of forming acronym in Indonesian Language based on morphology theory and internal syllable structure. The problems found in the processes of forming acronym in Indonesian Language are the absence of the acronym forming pattern, while the productivity of acronym in Indonesian Language grows fast and includes all disciplines. The result of this study showed that acronym processes can be classified into six groups as (1) coined syllable and syllable, (2) coined syllable and syllable \pm letters, (3) coined word and syllable \pm phonemes, (4) coined initial phonemes, (5) coined initial phonemes and syllable, and (6) coined initial phonemes and syllable, the processes has 83 type variant. Internal syllable structure respresent 7 types vocal consonant arrangement strucutre: $\mathrm{V}, \mathrm{CVC}, \mathrm{VC}, \mathrm{CCVC}, \mathrm{CCVC}, \mathrm{CV}, \mathrm{VVC}$, and $\mathrm{CCV}$.
\end{abstract}

Keywords: Acronym, Coined, Stucture, Internal, Syllable

\section{Introduction}

Indonesian is a flexible language, which is open to improvement and enrichment or addition of vocabulary. The rules in Indonesian language is not closed that it is possible for it to accept new vocabulary. In accordance with the opinion of Dardjowidjojo (1988:139) saying that the purpose of vocabulary enrichment allow, the symbolization of figurative concepts and the idea of modern life caused by the social cultural horizon extending beyond the limits of covered live hoods raising the importance words, terms, and expression with vocabulary expression affords.

In line with the above opinion, Kridalaksana (1982:54) argued that vocabulary expression in Indonesian can be done with six processes. The six vocabulary expansion processes are: (i) to adopted common word/phrases and give non particular meaning, (ii) to combine the common words, (iii) to form a word derived from a common root, (iv) to form term by analogy, (v) loan translation and (vi) adopted over from foreign languages or regional languages.

Many Indonesian vocabulary recently appeared often in the form of acronym. Acronym really is abbreviation according to Kridalaksana (1992:196), the language symptom shortening a phrase can be classified into five categories, namely: (1) abbreviation, (ii) fragment, (iii) acronym, (iv) contraction and (v) letter symbol.

Basically acronym is an abbreviation imposed as a word. The acronym is a universal phenomenon and found in all languages. The existence of acronym is a dynamic area of vocabulary of any language and is the source of the formation of new words.

The constant and intensive use of acronyms make acronyms equal to word in a language. As a result, the speaker no longer questioned the processed and the inclusion of acronyms into the vocabulary of a language. Accordingly the forming of acronym cannot be avoided and stopped as the formation of words in a language, acronyms continuous to evolve and grow over time.

The phenomenon of acronym appearance occured in Indonesia is the absence of clear and accurate rules in choosing the concept representing and represented in spelling a language. Therefore the acronyms formed is an abbreviation consisting of two words one more that it is easy to remember the user of Indonesian. The appearance of acronym not only happen in real conversation, but also in Indonesian press literacy, concern about the acronym following the Indonesian pers was raised by Atmahusumah, Atmajaya Lecturer at Dr. Sutomo Pers Institute Jakarta, who found at least 60 acronyms in the three daily, namely express Sumatera, Sriwijaya Post, morning news of 3 April 2006. The same thing was also confirmed by S. Takdir Ali Syahbana in Tempo (1990). "Dangerous, if Indonesian has too many acronyms". In line with the opinion of S. Takdir Alisyahbana, Gaban (2006) argued that, "Indonesian is endaugered by too many abbreviation and acronyms".

Further, Gaban explained that there are five things that could be the source of flooding acronyms usage. Firstly, the misconception about the concise writing, secondly, absurd obsession with abbreviations and acronyms, thirdly, complex way of thinking and inefficiency. Fourth, tendency to euphemism, fifth, do not comply with the guidelines of making abbreviation according to E.Y.D rule.

The forming of acronyms without a pattern in accordance with the order in the process of forming acronyms is a phenomenon descriptively explaining the circumstances which have not been established or 
standard of acronyms formation compared with the other word formation processes. This situation requires further research and study that include acronym formation as part of scientific activity. Therefore, this study is at the prescriptive level of a language in attempt to create a regular pattern of the acronym forming process which is a subsystem of the language.

Accordingly, the regularity of acronym patterns will present and reveal the pattern that can serve as guidelines for acronym formation process in the future methods.

\subsection{The Objectives of the Study}

The objectvives of the study are to:

1. described the formation structure pattern of acronym in Indonesian Language,

2. described the internal structure formation of internal structure of acronym in Indonesian Language.

\subsection{Scape of the Study}

The scope of this study focuses on the analysis of: Acronym in dictionary of acronyms initial and abreviation written by Agata Parsidi (1992).

\section{Data Analysis and Findings}

The data were classified into each category and organized as the center of analysis. First analyzed is acronym structure rules forming pattern and the second analysis is acronym syllable rules of Indonesian Language.

\subsection{Analysing the structure rules forming pattern of acronym in Indonesian} rules:

Language in six

\subsubsection{Coined Syllable and Syllable}

The forming acronym by coined syllable and syllable is the syllable from each component, coined at the begining, midle or end of the component: as:

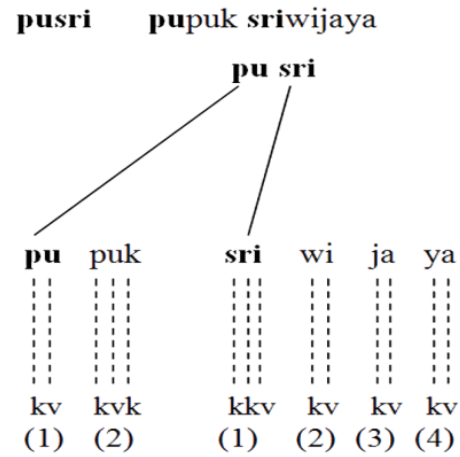

The coined syllable and syllable as in acronym pusri is the first syllable pu from the first component, combined with the first syllable sri from the second component, the result is acronim pusri this type has 12 variant types.

\subsubsection{Coined syllable and syllable \pm letters}

The forming acronym by coined syllable and syllable \pm letters is the syllable from each component, coined at the begining, midle or end of the component, and plus minus letters, as:

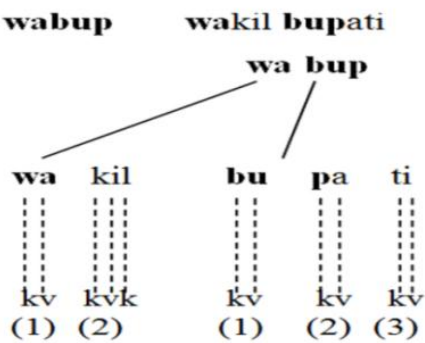


The coined syllable and syllable \pm letters as in wabup is; the first syllable plus the second syllable, from the first and second component. Wa is the first syllable from the first component, bu is the first syllable from the second component, and plus /p/, letter from the second syllable in the second component. This type has 60 variant types.

\subsubsection{Coined Word and Syllable}

The forming acronym by coined word and syllable is coined word as the first component plus first syllable of the second component, as:

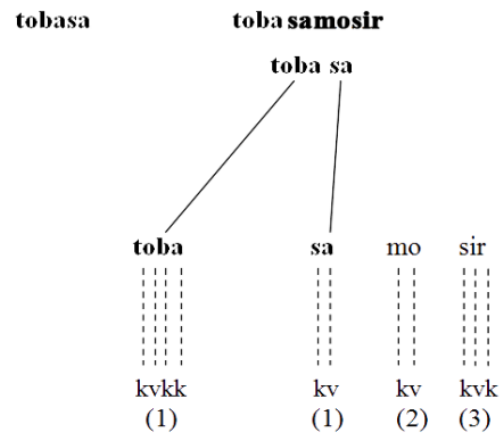

The coined word and syllable into acronym, in tobasa is; toba is word (first component) plus sa is first syllable from the second component. This type only has one type.

\subsubsection{Coined Word and Syllable \pm Phonemes}

The forming acronym by coined word and syllable \pm phonemes is coined word, as the first component; and syllable plus phonemes, as in:

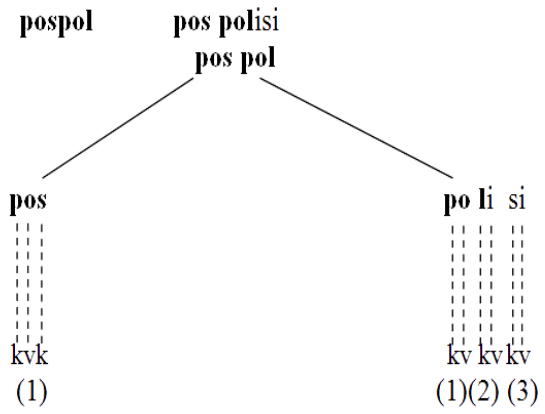

The coined word and syllable \pm phonemes in forming acronym in POSPOL, the first word is POI, also first component, $\mathbf{P O}$ is syllable from second component, and $\mathbf{L}$ is the first phonemes from second syllable in the second component. This type has 4 variant.

\subsubsection{Coined Initial Phonemes}

The forming acronym by coined initial phonemes from the components is the coined the initial phonemes to from the acronym as:

usu universitas sumatera utara

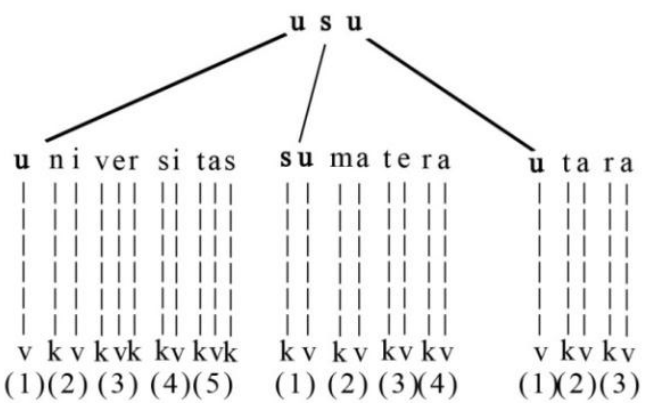


The coined initial phonemes as in USU is, $\mathbf{U}$, is the initial phonemes from the first component, $\mathbf{S}$ is the initial phonemes from the second component, and $\mathbf{U}$ is the initial phonemes from the third component. First initial phonemes from the component build the acronym, this type has 3 variant.

\subsubsection{Coined Initial Phonemes and Syllable}

The coined initial phonemes and syllable in forming acronym is the combination of initial phonemes and syllable of the component, as:

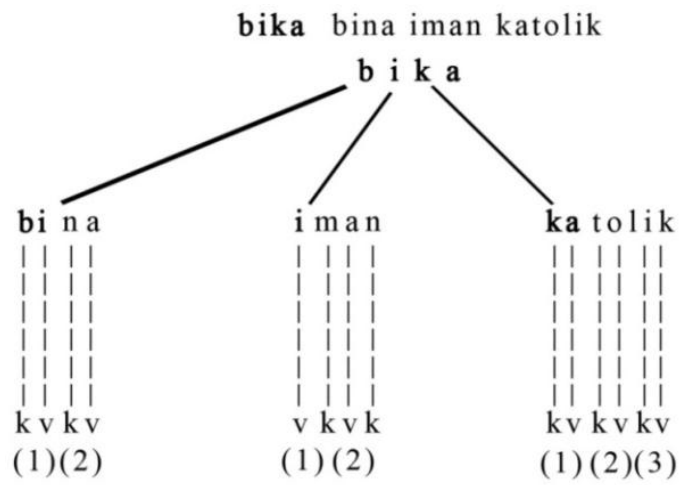

The coined initial phonemes and syllable as in bika is, $\mathbf{b}$ is initial phonemes of the first component, $\mathbf{i}$ is the initial phonemes of the second syllable, and ka is first syllable of the third component. This types has 3 variants.

\subsection{Analysing the Internal Rules Structure of Acronym in Indonesian Language}

In this care acronym in Indonesian Language is analyzed by examine the rules structure of internal acronyms case, which compased and of combined coined into acronym by arrangement vocal and consonant of the syllable theory. After analysing 105 acronym in Indonesian Language by arranging the vocal and consonant, its can be couluded as:

2.2.1 Acronym unej is consist of $\mathbf{u}$ as first syllable and nej as the second syllable. Acronym unej is analyzed as acronym with syllable $\mathbf{u}$ and $\mathbf{C V C} \quad$ syllable nej.

2.2.2 Acronym inkopram is consist of in as first syllable, ko as the second syllable and acronym inkopram is analyzed as acronym with VC sylable as in, $\mathbf{C V}$ as in $\quad$ ko, and CCVC as in pram.

2.2.3 Acronym distra is consist of; dis as first syllable and tra as the second syllable. Acronym distra is analyzed as acronym with VCV syllable as in dis, and CCV syllable as in tra.

2.2.4 Acronym polstranas is consist of pol, as first syllable, stra, as the second syllable, and nas as the third analyzed as. Acronym polstranas is analyzed as acronym with CVC syllable as in pol, CCCV syllable as in stra, and CVC syllable as in nas.

Acronym in Indonesian Language consist of seven type of internal syllable structure; $\mathbf{V}, \mathbf{C V C}, \mathbf{V C}$, CCVC, CV, VVC and CCCV.

\section{Conclution}

As the result of this study which is to examined the rules structure formation and the syllable rules internal structure of acronym in Indonesian Language, the conclution drawn as follows:

The result of the structure formation of acronym in Indonesian Language can be described in six pattern: (1) the structure formation coined syllable and syllable, it has 12 variant type, (2) the structure formation coined syllable and syllable \pm letters, it has 60 variant types, (3) the structure formation coined word and syllable, it has only type, (4) the structure formation coined word and syllable \pm phonemes, it has four variant, (5) the structure formation coined initial phonemes, it has three variant, and (6) the structure formation coined phonemes and syllable, it has three variants, all the structures rules type formation are 83 types.

The result of the Analysing the Internal Rules Structure of Acronym in Indonesian Language: (1) internal structure of acronym in vocal syllable as vocal $\mathbf{u}$ in $\mathbf{u}, \mathbf{n e j}$, and syllable structure consonant vocal and consonant as in nej. Acronym $\mathbf{u}$, nej, has two arrangement structure; vocal $\mathbf{u} /(\mathbf{v})$ and consonant vocal and consonant; nej (CVC). (2) internal structure of acronym in vocal consonant syllable as in (VC), consonant vocal syllable as ko $(\mathbf{C V})$, and consonant vocal consonant consonant syllable as in pram (CCVC). Acronym inkopram has three arrangement of syllable; VC,CV and CCVC. (3) internal structure of acronym in vocal consonant vocal and consonant consonant vocal as in dis (CVC) and consonant consonant vocal as in tra (CCV). Acronym distra has two arrangement internal structure syllable; consonant vocal consonant as in dis 
(CVC) and consonant consonant vocal (CCV) tra. (4) internal structure of acronym in consonant vocal consonat has been concluded above, the last syllable structure of internal acronym is consonant consonant and vocal $(\mathbf{C C C V})$ as in stra. Acronym polstranas consist of three syllable internal structure; CVC, CCCV, and CVC.

The internal rules structure syllable of acronym in Indonesian Language has seven types; V, CVC, VC, CCVC, CV, VVC, and CCCV.

\section{Refrences}

[1] Agata (1992). Kamus Akronim, initial dan singkatan: PT. Pustaka Utama Grafiti. Sie Issue No: KITLV-Lipi 241/92

[2] Aronoff, Mark, at. al. , 2005. What is Morphology? Victoria: Blackwell

[3] Bauer, Laurie., 1983. English Word Formation. Melbourne: Cambridge University Press.

[4] Booij, Geert. , 1997. Yearbook of Morphology 1997. Netherlands: Kluwer Academic Publishers.

[5] Botha, P. Rudolf. , 1988. Form and Meaning in Word Formation. New York: Cambridge University Press.

[6] Katamba, Francis. 19 89. Morphology. London: The Macmillan Press.

[7] Kridalaksana, Harimurti., 1982. Functions Language and Language Attitudes: set of Authorship. Flores: Nusa Indah.

[8] Kridalaksana, Harimurti., 1988. Several Principles natural blend of Indonesian lexeme d. Yogyakarta: Canisius.

[9] Kridalaksana, Harimurti. , 1996. Formation d of natural Indonesian word. Jakarta: Gramedia Pustaka Utama.

[10] Matthews, PH 1974. Morphology an Introduction to the Theory of Word Structure. Melbourne: Cambridge University Press.

[11] Plag, Ingo. , 2002. Word Formation in English. Ukraine: Cambridge University Press.

[12] Zahariev, Manuel., 2004. Acronyms. Dissertation Bucharest: Simon Fraser University. 